\title{
Sivas havzasındaki Eosen volkanizmasından kaynaklanan arsenik kirliliği: Yalıncak köyü (Hafik, Sivas) eski içme suyu kaynağı
}

\author{
Arsenic pollution caused by Eocene volcanism in the Sivas basin: The old \\ drinking water source of the Yalıncak village (Hafik, Sivas)
}

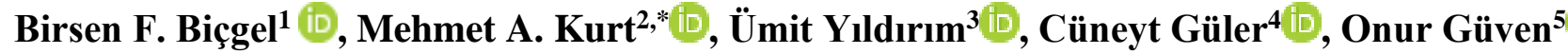

\begin{abstract}
${ }^{I}$ Mersin Üniversitesi, Fen Bilimleri Enstitüsü, Çevre Mühendisliği Anabilim Dall, Çiftlikköy Kampüsü, 33343, Yenişehir, Mersin, Türkiye
${ }^{2}$ Mersin Üniversitesi, Mühendislik Fakültesi, Çevre Mühendisliği Bölümü, Çiftlikköy Kampüsü, 33343, Yenişsehir, Mersin, Türkiye ${ }^{3}$ Bayburt Üniversitesi, Sanat ve Tasarım Fakültesi, Çevre Tasarımı Bölümü, Baberti Külliyesi, 69100, Bayburt, Türkiye

${ }^{4}$ Mersin Üniversitesi, Mühendislik Fakültesi, Jeoloji Mühendisliği Bölümü, Ciftlikköy Kampüsü, 33343, Yenisehir, Mersin, Türkive

${ }_{5}^{5}$ Mersin Üniversitesi, Fen Bilimleri Enstitüsü, Jeoloji Mühendisliği Anabilim Dall, Çiftlikköy Kampüsü, 33343, Yenişehir, Mersin, Türkiye
\end{abstract}

\begin{abstract}
Özet
Bu çalışmanın amacı, Yalıncak köyü (Hafik, Sivas) eski içme suyu kaynağındaki yüksek arsenik (As) derişiminin $(1512 \mu \mathrm{g} / \mathrm{L})$ kökeninin araştırılmasıdır. Bu amaçla, içme suyu kaynağının beslenim alanında yüzeyleyen kayaçlardan 48 adet örnek alınmıştır. Kayaç örneklerinin ana oksit içerikleri XRF yöntemiyle, mineralojik bileşimleri polarizan mikroskop ve XRD yöntemleriyle, minerallerin As derişimleri ise SEM-EDS yöntemi kullanılarak belirlenmiştir. Yapılan analizler sonucunda, sulardaki arseniğin kaynağının, piroksen ve plajiyoklaz mineralleri ile birlikte değişik köken ve boyuta sahip volkanik cam parçaları içeren tüfit birimi olduğu tespit edilmiştir. Kayaç örneklerindeki arsenik oksit $\left(\mathrm{As}_{2} \mathrm{O}_{3}\right)$ derişimleri $\% 0.01$ ve $\% 0.14$ arasında değişmekte olup bazı minerallerde \%14'e varan As mevcuttur. Çalışma sonucunda, bölgedeki yüzey ve yeraltı sularındaki arsenik kirliliğinin Sivas Havzası'ndaki Eosen yaşlı Bozbel formasyonu içindeki tüfitlerde bulunan FeAsS (arsenopirit) ve $\mathrm{BAsO}_{4}$ (borarsenat) minerallerinin çözünmesinden (sukaya reaksiyonu yoluyla) kaynaklandığı belirlenmiştir.
\end{abstract}

Anahtar kelimeler: Yalıncak köyü (Hafik), İçme suyunda arsenik, Tüfit, Arsenopirit, Borarsenat

\section{Giriş}

Antik çağlardan beri bilinen ve zehir olarak kullanılan arsenik (As), canlılar üzerinde ciddi olumsuz etkilere sahiptir. Yer kabuğunda bulunan birçok mineralin bileşeni olarak karşımıza çıkan arsenik, tarım, tıp, sanayi, vb. alanlarda yaygın olarak kullanılmaktadır [1]. Metaloid özelliği sergileyen As, doğada $+5,+3,0$ ve -3 değerlikleri alabilmekte ve atmosferde, toprakta, doğal sularda ve organizmalarda sıklıkla +3 ve +5 değerliklerde bulunmaktadır [2]. Doğada realgar ve orpiment gibi kendi mineralleri olan ve 200 'den fazla mineralin kristal yapısında bulunduğu bilinen arsenik [2]; iklimsel olaylar ve volkanik aktiviteler gibi doğal süreçlerle veya madencilik, tarımsal faaliyetler (pestisit ve insektisit kullanımı), fosil yakıtların yakılması ve cevherlerin ergitilmesi gibi antropojenik
Abstract

The aim of this study is to investigate the origin of the high concentration $(1512 \mu \mathrm{g} / \mathrm{L})$ of arsenic (As) in the old drinking water source of Yalıncak village (Hafik, Sivas). For this purpose, 48 samples were collected from the rocks outcropping in the recharge area of the drinking water source. The major oxide contents of the rock samples were determined by XRF method, mineralogical compositions by polarizing microscope and XRD methods and As concentrations of minerals were determined by using SEMEDS method. As revealed by these analyses, the source of arsenic in the waters of the region was found out to be tuffite unit, containing pyroxene and plagioclase minerals, as well as volcanic glass fragments of different origins and sizes. It has been detected that arsenic oxide $\left(\mathrm{As}_{2} \mathrm{O}_{3}\right)$ concentrations in rock samples vary between $0.01 \%$ and $0.14 \%$ and some minerals contain As up to $14 \%$. It was determined that arsenic pollution in surface and groundwater in the region was caused by the dissolution (by water-rock interaction) of $\mathrm{FeAsS}$ (arsenopyrite) and $\mathrm{BAsO}_{4}$ (boron arsenate) minerals found in the tuffites of the Eocene age Bozbel formation in the Sivas Basin.

Keywords: Yalıncak village (Hafik), Arsenic pollution drinking in water, Tuffite, Arsenopyrite, Boron arsenate

faaliyetler sonucunda da toprağa ve suya karışabilmektedir [3]. Su ve hava ile birlikte uzun mesafeler kat edebilen arsenik, akifer ortamı tarafindan sağlanan uygun indirgenme koşullarında çözünerek mobil hale gelebilmekte ve su kaynaklarında arsenik kirliliğine sebep olabilmektedir [4]. Ayrıca, arsenikli mineraller barındıran akifer kayaçlarında meydana gelen su-kayaç etkileşimi ve jeotermal ortamlardaki yüksek basınç/sıcaklık koşulları altında kolayca çözünerek yüzey ve yeraltı sularına karışarak kirliliğe neden olabilmektedir [2].

Günümüzde, dünyanın farklı bölgelerinde bulunan yeraltı ve yerüstü sularında, Dünya Sağlık Örgütü'nün [5] içme suyu sınır değerini $(10 \mu \mathrm{g} / \mathrm{L})$ aşan arsenik (As) derişimleri görüldüğü ve bu suları kullanmaktan başka imkânı olmayan milyonlarca insanın yüksek As

\footnotetext{
* Sorumlu yazar / Corresponding author, e-posta / e-mail: mehmetalikurt@ gmail.com (M. A. Kurt)

Geliş / Recieved: 04.05.2021 Kabul / Accepted: 30.06.2021 Yayımlanma / Published: 27.07.2021

doi: $10.28948 /$ ngmuh.932689
} 
derişimlerine maruz kaldığ 1 ve sağlıklarının bu durumdan olumsuz etkilendiği bilinmektedir. Yapılan çok sayıdaki bilimsel çalışma tarafindan da ortaya konulduğu üzere; Bangladeş, Çin, Hindistan, Macaristan, Romanya, Arjantin, Şili, Meksika, Tayvan, Amerika Birleşik Devletleri ve Vietnam gibi ülkelerde, özellikle yeraltı sularında oldukça yüksek arsenik derişimleri görülmektedir [2-4, 6-8]. Türkiye'nin özellikle Batı ve Orta Anadolu bölgelerinde yapılan çalışmalarda, yüksek derişimlerde arsenik içeren suların bulunduğu bildirilmiştir. Geçmişte volkanik aktivitenin yoğun olduğu bölgelerden biri olan Batı Anadolu'da yapılan çalışmalarda; Emet ve Kütahya içme suyu kaynağında $448 \mu \mathrm{g} / \mathrm{L}$ [9], Hisarcık ve Kütahya'da 510 $\mu \mathrm{g} / \mathrm{L}$ [10], İğdeköy-Kütahya-Emet dolaylarında $7745 \mu \mathrm{g} / \mathrm{L}$ [11], Bigadiç ve Balıkesir'de $911 \mu \mathrm{g} / \mathrm{L}$ [12] değerlerine ulaşan yüksek arsenik derişimleri tespit edilmiştir. Gemici vd. [12] tarafından yapılan çalışmada, arsenik derişiminin Bigadiç bor yatağı ve civarındaki yeraltı sularında yüksek olduğu vurgulanmış, bunun bor cevherleşmesi ile ilişkili olduğunu belirtilmiştir. Helvacı [13], Emet bor yatağı civarında yaptığı çalışmada, bor cevherlerinin ara katmanlarındaki tüfit ve kil örneklerinde yüksek derişimlerde arsenik bulunduğunu belirlemiştir. Türkiye'nin Orta Anadolu bölgesinde yer alan Kapadokya bölgesi de arsenik probleminin görüldüğü bölgelerden biri olup içme sularında yüksek derişimlerde (500 $\mu \mathrm{g} / \mathrm{L})$ arsenik bulunduğu ve kökeninin yörede yaygın olarak görülen volkanik oluşumlar, jeotermal sular, kömür içeren katmanlar ve piritli tortul kayaçlar olduğu belirtilmiştir [14]. Çeliker vd. [15], Uluova havzasında (Elazığ) yaptıkları çalışmada; yeraltı sularında $367 \mu \mathrm{g} / \mathrm{L}$, kaynak sularında $4842 \mu \mathrm{g} / \mathrm{L}$ ve akarsularda $31 \mu \mathrm{g} / \mathrm{L}$ 'ye varan yüksek derişimlerde arsenik tespit etmişler ve bölgedeki kirliliğin hem jeojenik kökenli hem de havzanın hidroloji-hidrojeokimyasını etkileyen antropojenik aktivitelerden kaynaklandığını belirtmişlerdir. Kurt vd. [16] ise Turhal (Tokat) dolaylarında yaptıkları çalışmada, bölgedeki antimonit cevherleşmesiyle ilişkili olarak yeraltı sularında belirgin bir arsenik kirliliğinin (429 $\mu \mathrm{g} / \mathrm{L}$ ) olduğunu belirtmişlerdir. Şimşek [17] tarafından Orta Anadolu bölgesinde bulunan Şarkışla (Sivas) Ovası'nda yapılan çalışmada, yeraltı sularında $0.5-345 \mu \mathrm{g} / \mathrm{L}$ arasında değişen derişimlerde arsenik tespit edilmiştir. Bu çalışmada, Şarkışla Ovası'ndaki arsenik kirliliğinin Pliyosen yaşlı kumtaşı ve Kuvaterner yaşlı alüvyon akiferlerindeki sukayaç etkileşimi sonucu meydana geldiği belirtilmiştir [17]. Kurt vd. [18]'nin Hafik ilçesine (Sivas) bağlı Pirhüseyin ve Yalıncak köyleri civarında yaptıkları çalışmada da benzer şekilde bazı kaynak ve şebeke sularında yüksek arsenik derişimleri (1064 $\mu \mathrm{g} / \mathrm{L})$ tespit edilmiştir. Kurt [19] tarafından aynı bölgede yapılan başka bir çalışmada ise, Yalıncak köyü şebeke suyunun kaynağında $1512 \mu \mathrm{g} / \mathrm{L}$ arsenik tespit edilmiş ve kaynağın Gürlevik Dağı eteklerinde yüzeyleyen volkanik breş-tüfit ve marn-kumtaşı-şeyl-kireçtaşı ardalanmasıyla karakterize olan Bozbel formasyonu içerisinden boşalım yaptığı vurgulanmıştır. Ancak bu çalışmada, sudaki arseniğin kökeninin belirlenmesine yönelik sistematik bir kayaç örneklemesi yapılmamıştır.

Bu çalışma, Yalıncak köyü (Hafik, Sivas) eski içme suyu kaynağındaki (Şekil 1) yüksek arsenik derişiminin kökenini (antropojenik veya jeojenik) belirlemek amacıyla yapılmıştır.
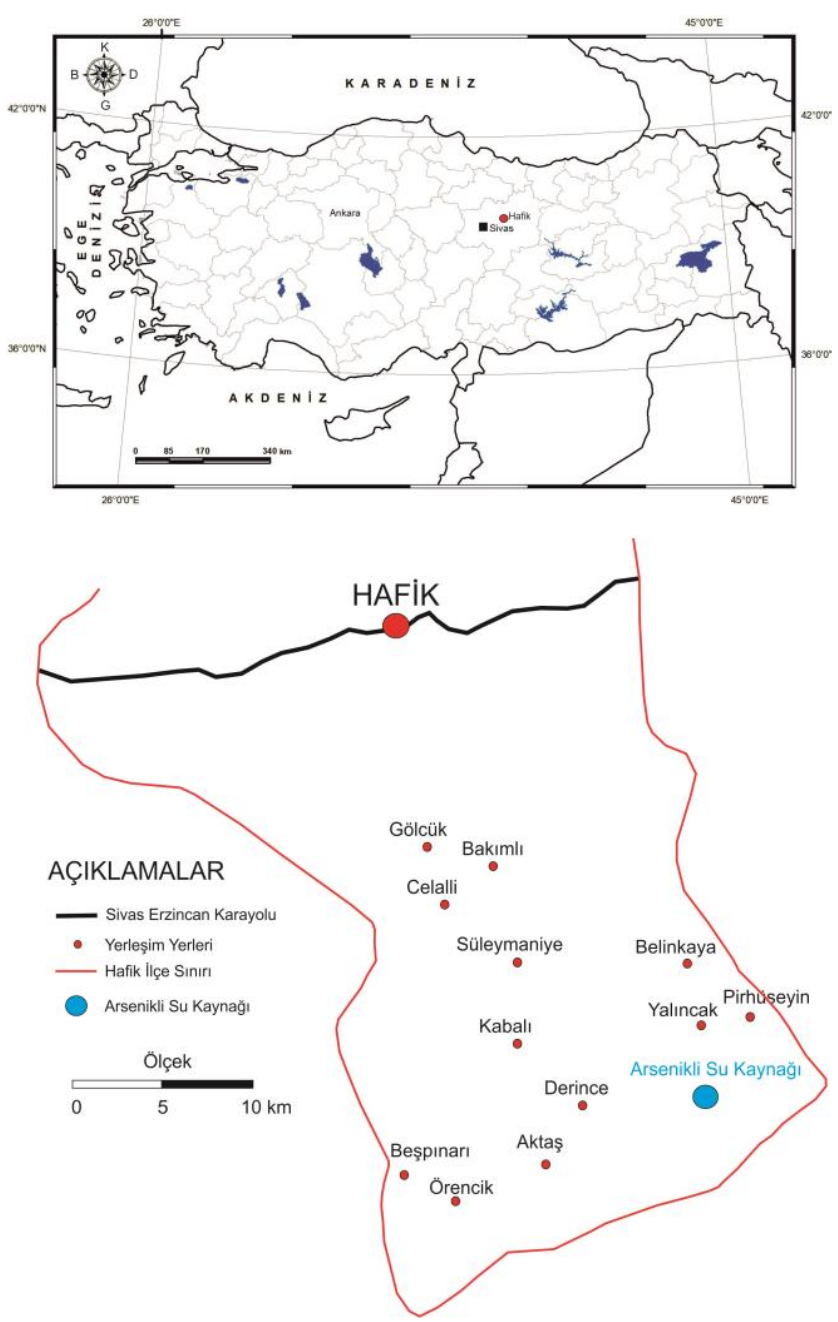

Şekil 1. Çalışma alanının yer bulduru haritası [20]

\section{Materyal ve metot}

Bu çalışma kapsamında, Ağustos 2017'de Yalıncak köyü (Hafik, Sivas) eski içme suyu kaynağından bir adet su örneği ve kaynağın beslenim alanında yüzeyleyen birimlerden 48 adet kayaç örneği alınmıştır. Kayaç örneklemesi, su kaynağının beslenim alanını kapsayacak şekilde iki ayrı istif içerisinde yapılmış olup birinci istiften 16, ikinci istiften ise 32 örnek alınmıştır. Alınan kayaç örnekleri diskli öğütücüde 1000 rpm devirde 2 dakika süre ile bileşen boyutları yaklaşık 80 mikrometre olacak şekilde öğütülmüştür. Elde edilen toz numune $1 / 10$ oranında selüloz ile homojen bir şekilde karıştırıldıktan sonra yaklaşık 40 tonluk bir basınçla preslenerek pastil haline getirilmiştir. Pastil numuneler X 1şını floresans spektroskopisi (XRF) ile analiz edilerek $\mathrm{Na}_{2} \mathrm{O}, \mathrm{MgO}, \mathrm{Al}_{2} \mathrm{O}_{3}, \mathrm{SiO}_{2}, \mathrm{P}_{2} \mathrm{O}_{5}, \mathrm{SO}_{3}, \mathrm{~K}_{2} \mathrm{O}, \mathrm{CaO}, \mathrm{TiO}_{2}, \mathrm{~V}_{2} \mathrm{O}_{5}$, $\mathrm{Cr}_{2} \mathrm{O}_{3}, \mathrm{MnO}, \mathrm{Fe}_{2} \mathrm{O}_{3}, \mathrm{NiO}, \mathrm{CuO}, \mathrm{ZnO}, \mathrm{As}_{2} \mathrm{O}_{3}, \mathrm{Rb}_{2} \mathrm{O}, \mathrm{SrO}$, $\mathrm{ZrO}_{2}$ ve $\mathrm{BaO}$ oksit değerleri belirlenmiştir. Kayaçların petrografik özelliklerini belirlemek ve kayaç adlandırması yapmak için ince kesitler hazırlanarak polarizan mikroskop altında incelenmiştir. Elektron mikroskobunda SEM-EDS yöntemiyle minerallerin arsenik içerikleri ve XRD tüm kayaç mineralojisi yöntemiyle örneklerin mineralojik 
Tablo 1. Mevcut çalışma kapsamında kullanılan analitik yöntemler ve kullanılan cihazlar

\begin{tabular}{|c|c|c|c|}
\hline Parametre & Birim & Analitik Yöntem & Kullanılan Cihaz, Marka, Model \\
\hline $\mathrm{pH}$ & Standart & $\begin{array}{l}\text { Elektrometrik metot }(\mathrm{pH} \text { probu) }(\mathrm{SM} \\
4500-\mathrm{H}+\mathrm{B})\end{array}$ & Portatif multiparametre cihazı (Hach Lange HQ40d) \\
\hline $\begin{array}{l}\text { Yükseltgenme-indirgenme } \\
\text { potansiyeli }\end{array}$ & $\mathrm{mV}$ & $\begin{array}{l}\text { Elektrometrik metot (Eh probu) (SM } \\
4500-\mathrm{H}+\mathrm{B})\end{array}$ & Portatif multiparametre cihazı (Hach Lange HQ40d) \\
\hline Çözünmüş oksijen & $\mathrm{mg} / \mathrm{L}$ & $\begin{array}{l}\text { Elektrometrik metot (Oksijen probu) } \\
\text { (SM 4500-O G) }\end{array}$ & Portatif multiparametre cihazı (Hach Lange HQ40d) \\
\hline Elektriksel iletkenlik & $\mu$ Siemens $/ \mathrm{cm}$ & $\begin{array}{l}\text { Elektrometrik metot (İletkenlik probu) } \\
\text { (SM } 2510 \text { B) }\end{array}$ & Portatif multiparametre cihazı (Hach Lange HQ40d) \\
\hline Anyon: $\mathrm{Cl}^{-}, \mathrm{F}^{-}, \mathrm{NO}_{3}^{-}, \mathrm{NO}_{2}^{-}, \mathrm{SO}_{4}^{-2}$ & $\mathrm{mg} / \mathrm{L}$ & TS EN ISO 14911 Su Kalitesi IC & İyon kromatografisi (Dionex IC 3000) \\
\hline Anyon: $\mathrm{HCO}_{3}{ }^{-}$ve $\mathrm{CO}_{3}{ }^{-2}$ & $\mathrm{mg} / \mathrm{L}$ & TS 3790 EN ISO 9963-1 (Titrimetrik) & Dijital büret \\
\hline Katyon: $\left.\mathrm{Ca}^{+2}, \mathrm{Mg}^{+2}, \mathrm{Na}^{+}, \mathrm{K}^{+}, \mathrm{NH}_{4}^{+}\right)$ & $\mathrm{mg} / \mathrm{L}$ & TS EN ISO 14911 Su Kalitesi IC & İyon kromatografisi (Dionex IC 3000) \\
\hline İz elementler (kayaç ve su) & $\begin{array}{l}\mathrm{mg} / \mathrm{kg} \text { veya } \\
\mu \mathrm{g} / \mathrm{kg}\end{array}$ & TS EN ISO 17294-2 & $\begin{array}{l}\text { İndüktif eşleşmiş plazma kütle spektrometresi } \\
\text { (Agilent } 7500 \text { ce ICP-MS) }\end{array}$ \\
\hline Kayaçlarda oksit yüzdeleri & $\%$ & WD-XRF Yöntemi (TS EN 15309) & XRF (Rigaku ZSX Primus II) \\
\hline Kayaç mineralojisi & - & $\begin{array}{l}\text { XRD Yöntemi (SM tüm kayaç } \\
\text { mineralojisi) }\end{array}$ & XRD (Rigaku Smart Lab) \\
\hline Görüntüleme ve EDS & - & SEM-EDS & SEM (Zeis) \\
\hline İnce kesit & - & Polarizan mikroskop & Olympus \\
\hline
\end{tabular}

bileşimleri belirlenmiştir. Arsenikli kaynaktan su örneklemeleri için $250 \mathrm{ml}$ 'lik iki adet polietilen (PE) numune kabı kullanılmıştır. Alınan numuneler filtrelendikten $(0,45 \mu \mathrm{m}$ açıklıklı) sonra birinin içerisine $\mathrm{pH}$ $<2$ olacak şekilde $2 \mathrm{ml} \mathrm{HNO}_{3}$ arazide eklenmiştir. Yalıncak köyü eski içme suyu kaynağından alınan su örneğinin $(n=$ 1) fiziksel ( $\mathrm{pH}$, iletkenlik, yükseltgenme-indirgenme potansiyeli) ve kimyasal özellikleri (anyon, katyon, iz elementler) belirlenmiştir. Çalışma kapsamında yapılan analizlere ait yöntemler Tablo 1'de sunulmuştur.

\section{Bulgular ve tartışma}

\section{1 Çalışma alanının jeolojisi}

Hafik ilçesi ve civarının temel kayaçlarını, Sivas Havzası'nın temelini oluşturan Paleozoyik yaşlı metamorfitlerle Üst Kretase yaşlı ofiyolitik kayaçlar oluşturmaktadır (Şekil 2). Bu temel üzerinde, kalınlığı yaklaşık 6 km'ye varan ve çoğunluğunu kırıntılı çökellerin oluşturduğu Üst Kretase-Tersiyer yaşlı istifler yer almaktadır [21]. Bu istifin en yaşlı birimi Üst KretasePaleosen yaşlı Gürlevik formasyonu olup bu formasyon marn ara katmanlı kireçtaşlarından oluşmaktadır [21]. Bu birimin üzerinde, Eosen yaşlı Kozluca ve Bozbel formasyonları yer almaktadır. Kozluca formasyonu, kumtaş1, kireçtaş1, marn ve şeylden oluşurken [21], Bozbel formasyonu, konglomera, tüfit ve volkanik breş, kumtaş1, kumlu kireçtaşı ve kiltaşı ardalanmasından oluşmaktadır [22]. Bozbel formasyonuyla aynı yaşlı ve bu formasyonla yer yer ara katmanlı Karadağ bazaltı bölgenin bazı kesimlerinde görülmektedir. Bozbel formasyonu içerisindeki volkanik breş ve tüfit seviyeleri olası olarak Karadağ volkanizmasından kaynaklanmaktadır. Bölgedeki diğer yaygın kaya birimleri ise Oligosen yaşlı Selimiye formasyonu ve Miyosen yaşlı Hafik formasyonudur. Selimiye formasyonu, tabanda masif jipslerle başlar ve üst düzeylere doğru çakıltaşı, kumtaş1, silttaşı ve çamurtaşı ardışımlı, kalın-orta ve orta-ince katmanlıdır [22, 23]. Selimiye formasyonunu üzerleyen Hafik formasyonu ise bölgede oldukça geniş yayılımlı olup formasyonun üst seviyelerini oluşturan jips tabakaları, alt seviyelerde kumtaşı, silttaşı, konglomera seviyeleri ile hem ardalanmalı, hem de yanal geçişli olarak yer almaktadır [24]. Havzadaki istife bakıldığında, bölgedeki kaynak ve içme sularındaki As artışına kaynaklık edebilecek birimlerin olduğu görülmektedir. Bunlar, bölgede yaygın olarak görülen evaporitik kayaçlar (jips) ve volkanikvolkanoklastik ürünler (bazalt, tüfit ve volkanik breş) veya yüzeyde görünmeyen arsenik içeren cevherleşmeler (sülfitler) olabilir. Yüksek As içeren Yalıncak köyü eski içme suyu kaynağı, Bozbel formasyonu içerisinden boşalım yapmaktadır. Kurtman [22], Bozbel Dağı ile Karababa Dağ1 arasında Bozbel formasyonundan aldığ 1 kesitte, alttan üste doğru sırasıyla; tüfit ve volkanik breş ardalanması, marnkumtaş1-şeyl-kireçtaşı ardalanması, jips ve kireçtaşı mercekleri içeren marn seviyesi, tüfit ve volkanik breş ardalanması ve ince tabakalı marn-kumtaş1-şeyl-kireçtaş1 ardalanması gibi birimleri belirlemiştir.

\subsection{Kayaçların XRF oksit analizleri}

Yalıncak köyü eski içme suyu kaynağının beslenim alanında yer alan kayaçların iki farklı seviyesinden (1. istif ve 2. istif) örnekleme yapılmıştır. 1. ve 2. istifteki kayaçların ana oksit derişimlerinin en düşük, en yüksek ve ortalama oksit değerleri Tablo 2'de sunulmuştur. Birinci istifteki kayaçlarda, $\mathrm{SiO}_{2}$ en yüksek derişimi sergilemekte olup en düşük, en yüksek ve ortalama derişimleri yüzde (\%) olarak sirasıyla 40.41, 47.87 ve 44.20'dir (Tablo 2). Bunun yanı sıra, 1. istifteki kayaçlarda $\mathrm{Al}_{2} \mathrm{O}_{3}$ 'ün en düşük, en yüksek ve ortalama değerleri (\% cinsinden) sirasıyla $13.19,16.33$ ve 15.54'tür (Tablo 2). $\mathrm{Fe}_{2} \mathrm{O}_{3}$ 'ün en düşük, en yüksek ve ortalama değerleri (\% cinsinden) ise $8.53,13.04$ ve 11.39 olarak belirlenmiştir (Tablo 2). Bu istifte, $\mathrm{MgO}^{\prime}$ ya ait en düşük, en yüksek ve ortalama değerler (\% cinsinden) ise sirasıyla 5.67, 7.97 ve $6.87^{\prime}$ 'dir. Birinci istifte $\mathrm{As}_{2} \mathrm{O}_{3}$ ise, sekiz örnekte ölçüm limiti (\%0.003) altında gözlenirken, sekiz örnekte ise $\% 0.01$ ile $\% 0.14$ aralığında derişimler sergilemiştir (Tablo 2). 


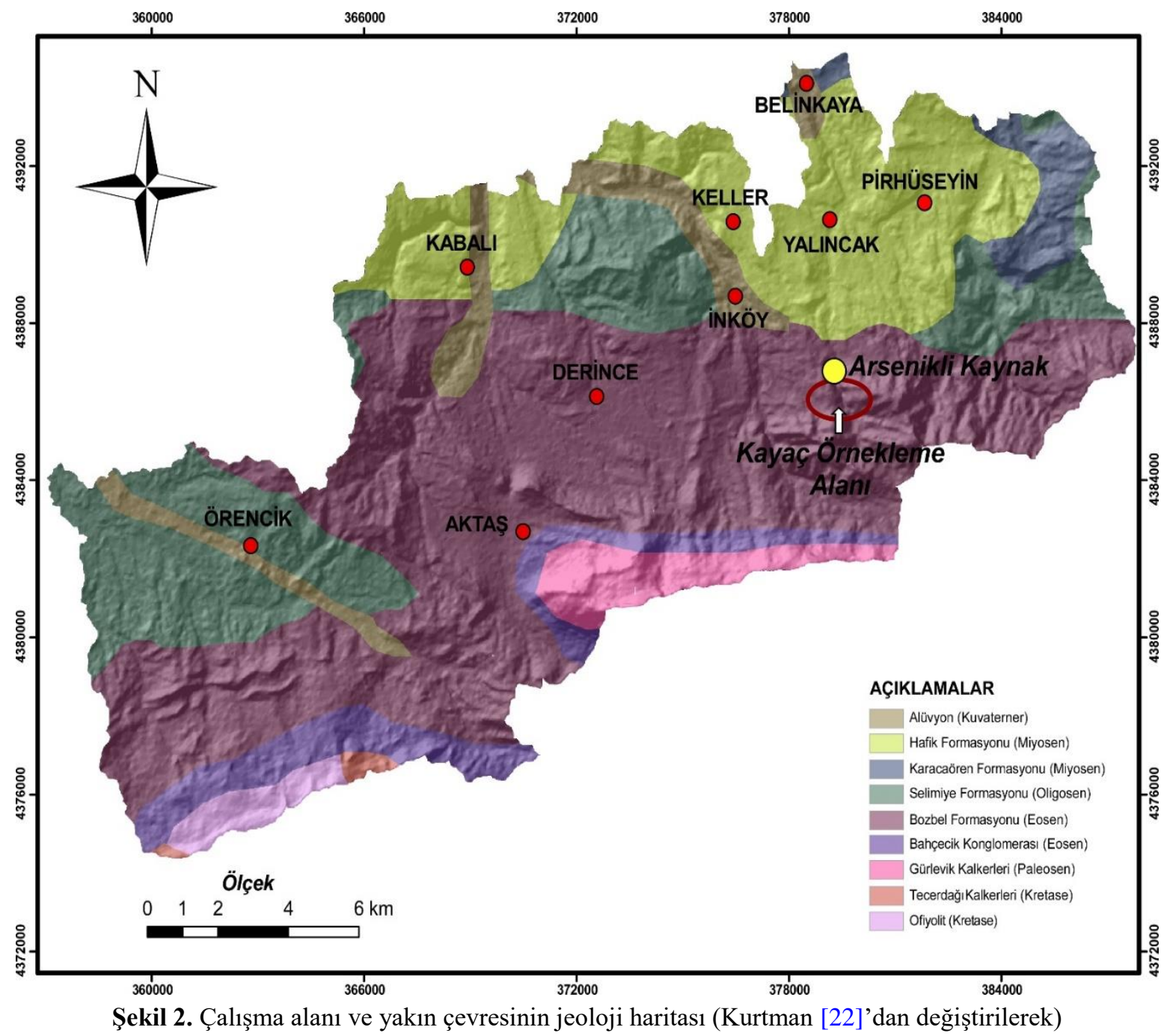

2. istif olarak adlandırılan kayaçların analiz sonuçlarına göre, $\mathrm{SiO}_{2}, \mathrm{Al}_{2} \mathrm{O}_{3}, \mathrm{Fe}_{2} \mathrm{O}_{3}$ ve $\mathrm{MgO}$ en yüksek derişime sahip oksitler olarak öne çıkmaktadır (Tablo 2). En düşük, en yüksek ve ortalama $\mathrm{SiO}_{2}$ (\% cinsinden) sirasiyla 39.21, 63.23 ve 44.32 'dir. $\mathrm{Al}_{2} \mathrm{O}_{3}$ 'ün en düşük, en yüksek ve ortalama değerleri (\% cinsinden) sirasıyla $12.53,16.82$ ve 14.74 'tür (Tablo 2). $\mathrm{Fe}_{2} \mathrm{O}_{3}$ 'ün en düșük, en yüksek ve ortalama değerleri \% olarak sırasıyla 5.11, 14.21 ve 11.74 olarak belirlenmiştir (Tablo 2). MgO’ya ait en düşük, en yüksek ve ortalama değerler (\% olarak) ise sirasıyla 4.32, 9.18 ve 6.94'tür. Bu istifte bulunan kayaçların hiçbirinde ölçüm limiti olan \%0.003'ten daha yüksek derişimde arsenik oksit $\left(\mathrm{As}_{2} \mathrm{O}_{3}\right)$ tespit edilememiştir (Tablo 2).

\subsection{Kayaç mineralojisi}

$\mathrm{Bu}$ bölümde, alınan kayaç örneklerinin mineralojisini tanımlamaya yönelik olarak yapılan analizlere ait sonuçlar aktarılmıştır.

\subsubsection{Petrografik analizler}

Yalıncak köyü eski içme suyu kaynağının beslenim alanında yer alan kayaçların mineralojik bileşimlerini belirlemek ve kayaç adlandırmalarını yapmak amacıyla alınan örneklerden ince kesitler hazırlanmış ve polarizan mikroskopta petrografik incelemeye tabi tutulmuşlardır. Petrografik incelemeler sonucunda, kayaçların plajiyoklaz ve piroksen kristal fazlarının yanı sıra, farklı köken ve boyutta kayaç parçaları ile volkanik cam içerdikleri belirlenmiştir (Şekil 3). Bu içeriklere göre; kayaç örnekleri tüfit olarak adlandırılmıştır. Kayaç örneklerinde alterasyon yaygın olarak görülmekte olup bunlar karbonatlaşma, kloritleşme ve serizitleşme türü alterasyonları işaret etmektedir (Şekil 3).

\subsubsection{XRD analizleri}

Yalıncak köyü eski içme suyu kaynağının beslenim alanındaki kayaç örnekleri içerisinde en yüksek $\mathrm{As}_{2} \mathrm{O}_{3}$ derişimine (\%0.14) sahip örneğin XRD analizi yapılmış olup XRD pikleri ve belirlenen mineral fazları Şekil 4'te görülmektedir. XRD analiz sonuçlarına göre; bu kayaç örneği, Ca-plajiyoklaz (anortit), Na-plajiyoklaz (albit), klorit, ortopiroksen, klinopiroksen, arsenopirit ve borarsenat mineral fazlarını içermektedir. Elde edilen bu sonuçlara göre, Yalıncak köyü eski içme suyu kaynağındaki yüksek 
arsenik derişimi, büyük olasılıkla 1. İstifte bulunan tüfitlerdeki arsenopirit $(\mathrm{FeAsS})$ ve borarsenat $\left(\mathrm{BAsO}_{4}\right)$ minerallerinden kaynaklanmaktadır (Şekil 4).

Tablo 2. Kayaçların en düşük, en yüksek ve ortalama oksit içerikleri ve ateş kaybı değerleri

\begin{tabular}{|c|c|c|c|c|c|c|}
\hline $\begin{array}{l}\text { Oksit } \\
(\%)\end{array}$ & $\begin{array}{l}\text { 1. İstif } \\
(n=16)\end{array}$ & & & $\begin{array}{l}\text { 2. İstif } \\
(n=16)\end{array}$ & & \\
\hline & $\begin{array}{l}\text { En } \\
\text { düşük }\end{array}$ & $\begin{array}{l}\text { En } \\
\text { yüksek }\end{array}$ & Ort. & $\begin{array}{l}\text { En } \\
\text { düşük }\end{array}$ & $\begin{array}{l}\text { En } \\
\text { yüksek }\end{array}$ & Ort. \\
\hline $\mathrm{Na}_{2} \mathrm{O}$ & 1.36 & 4.25 & 2.50 & 0.73 & 3.45 & 2.32 \\
\hline $\mathrm{MgO}$ & 5.67 & 7.97 & 6.87 & 4.32 & 9.18 & 6.94 \\
\hline $\mathrm{Al}_{2} \mathrm{O}_{3}$ & 13.19 & 16.33 & 15.54 & 12.53 & 16.82 & 14.74 \\
\hline $\mathrm{SiO}_{2}$ & 40.41 & 47.87 & 44.20 & 39.21 & 63.23 & 44.32 \\
\hline $\mathrm{P}_{2} \mathrm{O}_{5}$ & 0.22 & 0.44 & 0.35 & 0.15 & 0.37 & 0.29 \\
\hline $\mathrm{SO}_{3}$ & 0.05 & 2.64 & 0.35 & 0.04 & 0.13 & 0.06 \\
\hline $\mathrm{K}_{2} \mathrm{O}$ & 0.47 & 3.59 & 2.40 & 0.31 & 3.65 & 1.68 \\
\hline $\mathrm{CaO}$ & 6.40 & 14.92 & 10.11 & 3.74 & 22.93 & 11.61 \\
\hline $\mathrm{TiO}_{2}$ & 0.94 & 1.26 & 1.06 & 0.65 & 1.22 & 0.91 \\
\hline $\mathrm{V}_{2} \mathrm{O}_{5}$ & 0.05 & 0.10 & 0.06 & 0.05 & 0.07 & 0.06 \\
\hline $\mathrm{Cr}_{2} \mathrm{O}_{3}$ & 0.02 & 0.06 & 0.03 & 0.02 & 0.07 & 0.04 \\
\hline $\mathrm{MnO}$ & 0.16 & 0.22 & 0.20 & 0.12 & 0.28 & 0.22 \\
\hline $\mathrm{Fe}_{2} \mathrm{O}_{3}$ & 8.53 & 13.04 & 11.39 & 5.11 & 14.21 & 11.74 \\
\hline $\mathrm{NiO}$ & 0.01 & 0.04 & 0.02 & 0.01 & 0.04 & 0.02 \\
\hline $\mathrm{CuO}$ & 0.02 & 0.04 & 0.02 & 0.01 & 0.03 & 0.02 \\
\hline $\mathrm{ZnO}$ & 0.01 & 0.02 & 0.02 & 0.01 & 0.02 & 0.02 \\
\hline $\mathrm{As}_{2} \mathrm{O}_{3}$ & $<0.003$ & 0.14 & 0.04 & $<0.003$ & $<0.003$ & $<0.003$ \\
\hline $\mathrm{Rb}_{2} \mathrm{O}$ & 0.01 & 0.10 & 0.02 & 0.01 & 0.01 & 0.01 \\
\hline $\mathrm{SrO}$ & 0.03 & 0.10 & 0.06 & 0.02 & 0.59 & 0.06 \\
\hline $\begin{array}{l}\text { Ateş } \\
\text { kayb1 }\end{array}$ & 3.93 & 6.76 & 4.77 & 2.87 & 12.15 & 4.92 \\
\hline
\end{tabular}

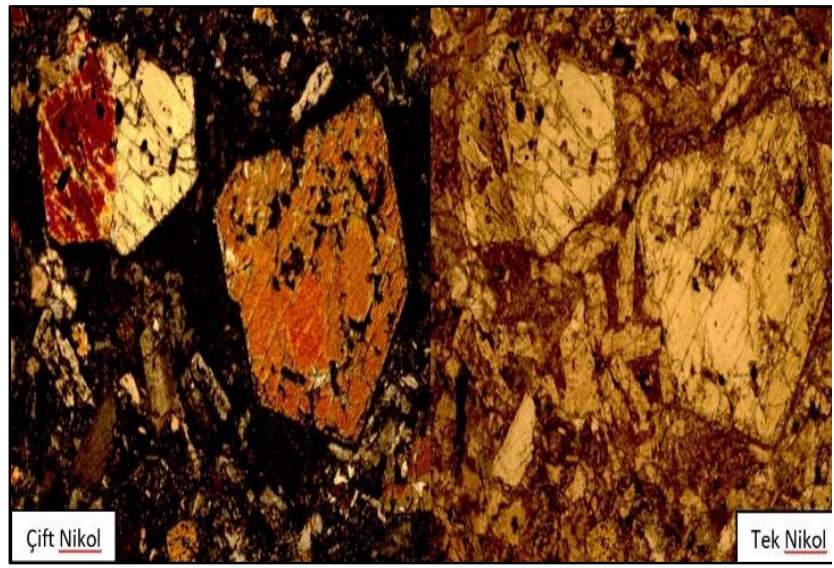

Şekil 3. Tüfitlerin polarizan mikroskop altında çekilen çift ve tek nikol görüntüleri

\subsubsection{SEM analizleri}

Yüksek miktarda arsenik oksit içeren tüfit örneklerindeki mineral fazlarının morfolojisini görüntülemek ve mineral içeriğinde bulunan elementel arseniğin miktarını saptamak amacıyla SEM analizleri yapılmıştır. Elde edilen SEM görüntüsünde (Şekil 5), arsenikli tüfit örneğinin mikro gözenekli bir yapıda olduğu görülmektedir. SEM görüntüsünün yanı sıra, EDS (enerji dağılımlı spektrometre) dedektörü kullanılarak minerallerin yarı kantitatif kimyasal analizi de yapılmış ve minerallerin kimyasal bileşimleri hakkında bilgi elde edinilmeye çalışılmıştır.
En yüksek arsenik oksit $\left(\mathrm{As}_{2} \mathrm{O}_{3}\right)$ içeren örnekten $(\% 0.14)$ elde edilen EDS spektrumu ve noktasal yarı kantitatif analiz sonuçları Şekil 6'da verilmiştir. Bu analize göre; en yüksek elementel arsenik (As) içeren noktada; \%33.34 Fe, \%14.02 As, \%9.83 Si, \%6.50 Ca, \%1.63 B ve \%1.46 S tespit edilmiştir. Elde edilen bu elementel derişim değerleri de tüfitlerdeki arsenopirit ve borarsenat mineralleri varlığını doğrulamaktadır

\subsection{Yalıncak köyü eski içme suyu kaynağının fiziksel ve kimyasal özellikleri}

Bu çalışma kapsamında, Yalıncak köyü eski içme suyu kaynağından alınan su örneğinde, yerinde $\mathrm{pH}$, Eh ve elektriksel iletkenlik gibi fiziksel parametreler ölçülmüş ve laboratuvarda majör katyon/anyon ve iz element analizleri gerçekleştirilmiştir. Oldukça düşük sayılabilecek elektriksel iletkenlik $(224 \mu \mathrm{S} / \mathrm{cm})$ ve Eh $(-67.5 \mathrm{mV})$ değerlerine sahip olan bu kaynak suyu, alkali su $(\mathrm{pH}=8.12)$ sinifina girmektedir. Bu su kaynağında, sodyum $\left(\mathrm{Na}^{+}\right)$, magnezyum $\left(\mathrm{Mg}^{+2}\right)$, potasyum $\left(\mathrm{K}^{+}\right)$, kalsiyum $\left(\mathrm{Ca}^{+2}\right)$ ve silis $(\mathrm{Si})$ katyonlarına ait değerler sırasıyla (mg/Lcinsinden) 20.45, $4.24,0.94,25.23$ ve 8.75 olarak belirlenmiştir. Su örneğinde analiz edilen florür $\left(\mathrm{F}^{-}\right)$, klorür $\left(\mathrm{Cl}^{-}\right)$, nitrit $\left(\mathrm{NO}_{2}{ }^{-}\right)$, nitrat $\left(\mathrm{NO}_{3}{ }^{-}\right)$, fosfat $\left(\mathrm{PO}_{4}^{-3}\right)$, sülfat $\left(\mathrm{SO}_{4}^{-2}\right)$, karbonat $\left(\mathrm{CO}_{3}^{-2}\right)$ ve bikarbonat $\left(\mathrm{HCO}_{3}{ }^{-}\right)$anyonlarının derişimleri ise sırasıyla (mg/L cinsinden) $0.06,2.96,<0.01,0.32,<0.01,29.72,0.00$ ve 94.5 olup sülfat ve bikarbonat en yüksek değerleri sergilemektedir. Arsenikli su örneğinin yapılan elektronötralite hesabına göre iyon dengesinin $\% 0,18$ olduğu belirlenmiştir. Yalıncak köyü eski içme suyu kaynağından alınan su örneğinin bazı iz element değerleri $(\mu \mathrm{g} / \mathrm{L}$ cinsinden $)$; bor $(\mathrm{B}=2013)$, titanyum $(\mathrm{Ti}=58.35)$, demir $(\mathrm{Fe}$ $=192.43)$, arsenik $(\mathrm{As}=1512)$, stronsiyum $(\mathrm{Sr}=169.8)$, brom $(\mathrm{Br}=9.66)$ 'dir. Bu kaynak suyunda, özellikle As ve $\mathrm{B}$ miktarları ulusal ve uluslararası içme suyu standartlarının oldukça üzerindedir. Bu suda, As ve B elementlerine ait derişimlerin yüksek olması, akiferdeki arsenopirit ve borarsenat minerallerinin varlığıyla yakından ilişkilidir. Oldukça düşük $(\mu \mathrm{g} / \mathrm{L}$ cinsinden) baryum $(\mathrm{Ba}=3.22)$, molibden $(\mathrm{Mo}=2.08)$ ve nikel $(\mathrm{Ni}=1.06)$ derişimlerine sahip olan kaynakta, alüminyum $(\mathrm{Al}), \operatorname{krom}(\mathrm{Cr})$, bakır $(\mathrm{Cu})$, çinko $(\mathrm{Zn})$, kadmiyum $(\mathrm{Cd})$ ve kurşun $(\mathrm{Pb})$ derişimleri ise 1 $\mu \mathrm{g} / \mathrm{L}$ 'nin altındadir.

\subsection{Tartışma}

Kurt vd. [18]'in, Pirhüseyin ve Yalıncak köyleri civarında yaptığı çalışmada, bölgedeki yüzey ve yeraltı sularında belirgin bir As kirliliğinin olduğu belirtilmiştir. Bu çalışmada [18], bu arsenik kirliliğinin bölgedeki arazi kullanımına dayanarak antropojenik olmadığı, litolojik olabileceği belirtilmiş, ancak kirliliğin kaynağı net olarak ortaya konulmamıştır.

Yalıncak Köyü arsenikli eski içme suyu kaynağının beslenim alanından iki farklı seviyede yapılan örnekleme ve bunların XRF analiz sonuçlarına göre, 1. istifte yer alan tüfitlerin bazı seviyelerinde yüksek arsenik oksit olmasına karşın, 2. istif içerisinde dedeksiyon limitinin üzerinde arsenik oksit bulunmamıştır. İki istifin analiz sonuçları karşılaştırıldığında, hemen hemen tüm sonuçların oldukça benzer oldukları görülmektedir. 


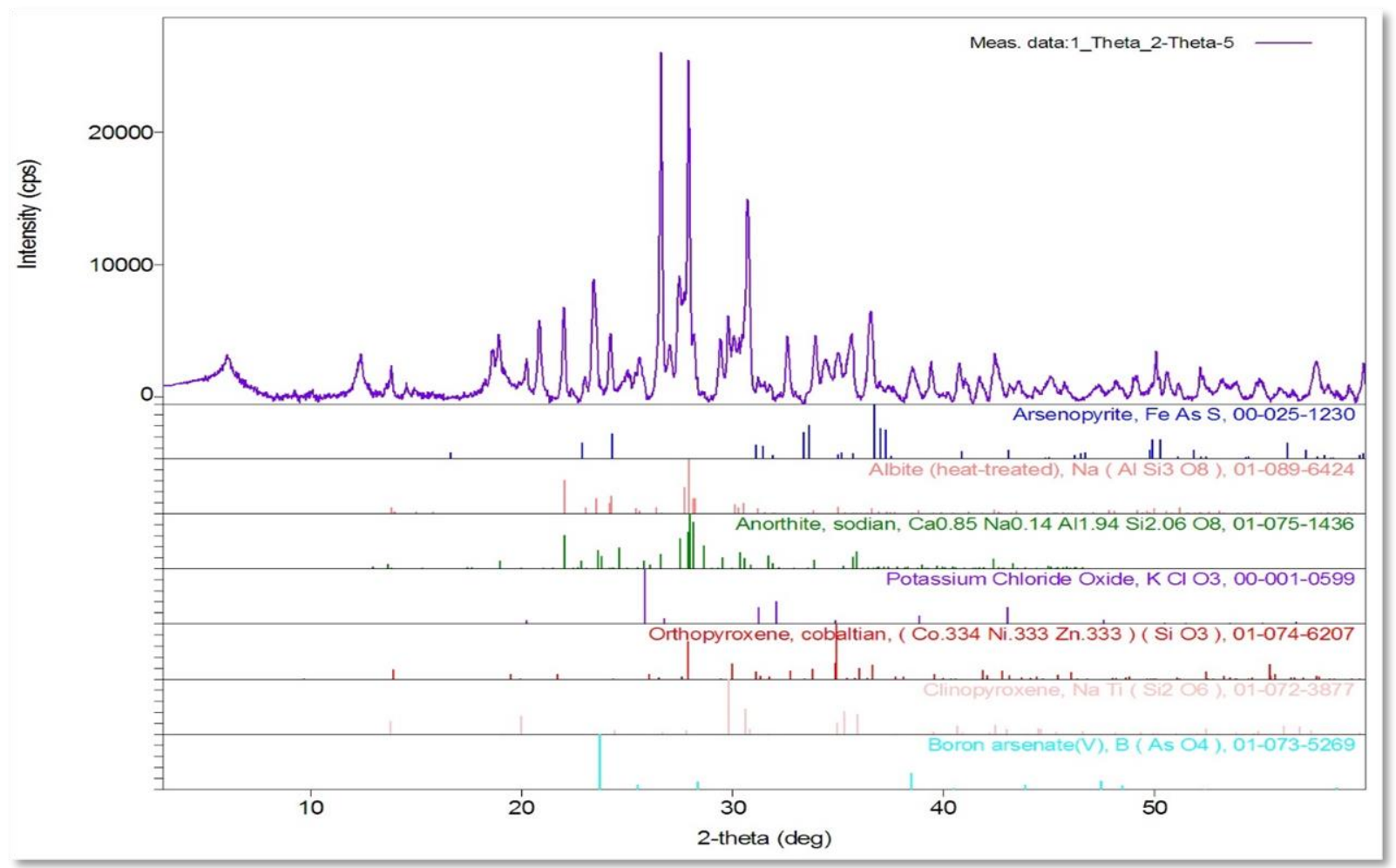

Şekil 4. Arsenikli tüfit örneğine ait XRD pikleri ve belirlenen mineral fazları

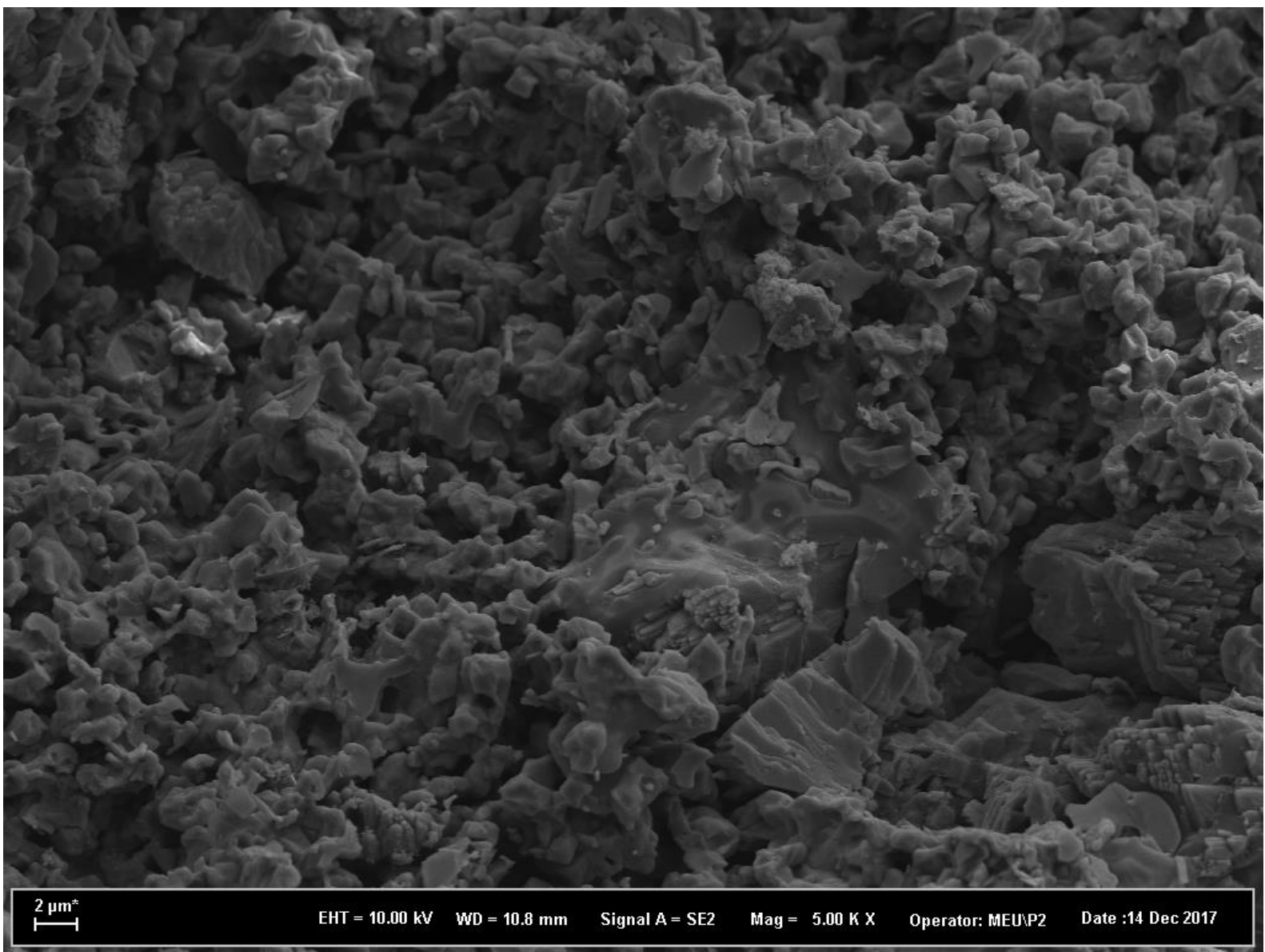

Şekil 5. Arsenikli tüfit örneğine ait SEM görüntüsü 


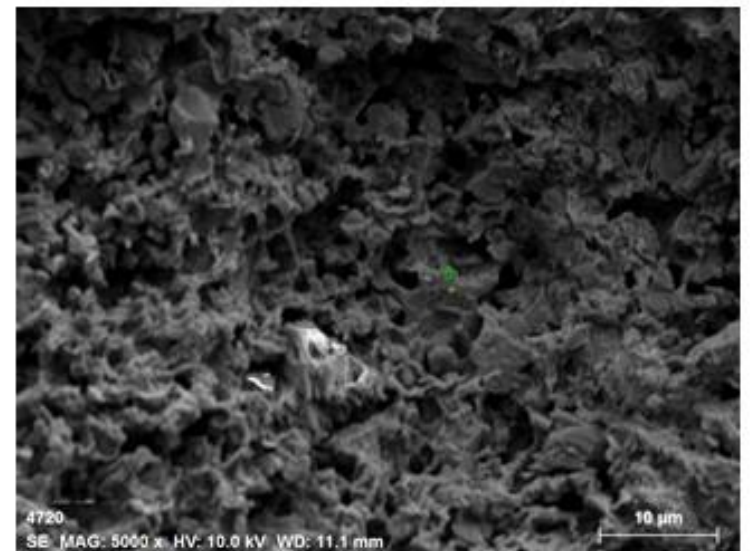

\begin{tabular}{|c|c|c|c|c|c|}
\hline El & AN & Series & $\begin{array}{l}\text { unn. C } \\
\text { [wt. \&] }\end{array}$ & $\begin{array}{r}\text { norm. C } \\
\text { [wt.8] }\end{array}$ & $\begin{array}{l}\text { Atom. } \\
\text { [at.8] }\end{array}$ \\
\hline $\mathrm{Fe}$ & 26 & K-series & 23.41 & 33.34 & 30.31 \\
\hline Pt & 78 & M-series & 15.69 & 22.35 & 5.82 \\
\hline As & 33 & L-series & 9.84 & 14.02 & 9.50 \\
\hline Si & 14 & $\mathrm{~K}$-series & 6.90 & 9.83 & 17.77 \\
\hline $\mathrm{Ca}$ & 20 & K-series & 4.56 & 6.50 & 8.23 \\
\hline Pd & 46 & L-series & 4.19 & 5.96 & 2.84 \\
\hline 0 & 8 & K-series & 3.45 & 4.91 & 15.58 \\
\hline B & 5 & K-series & 1.14 & 1.63 & 7.65 \\
\hline s & 16 & K-series & 1.03 & 1.46 & 2.31 \\
\hline
\end{tabular}

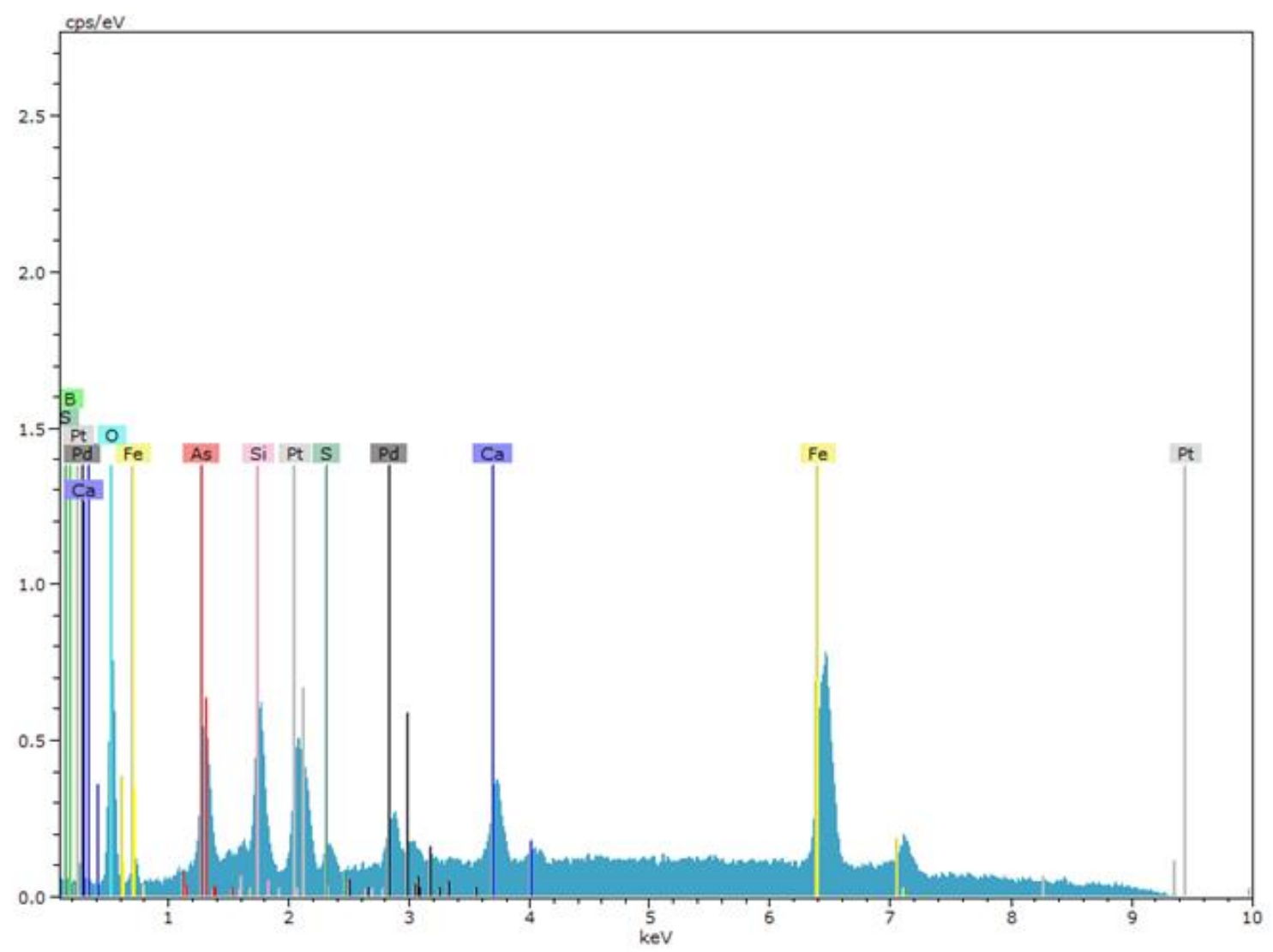

Şekil 6. Arsenikli tüfit örneğine ait EDS spektrumu ve noktasal yarı kantitatif analiz sonuçları

Buna karşın 1. ve 2. istifin ortalama $\mathrm{As}_{2} \mathrm{O}_{3}$ değerleri $(\%$ olarak) sirasıyla 0.04 ve $<0.003 ; \mathrm{SO}_{3}$ değerleri sirasıyla 0.35 ve 0.06 olup iki istif $\mathrm{As}_{2} \mathrm{O}_{3}$ ve $\mathrm{SO}_{3}$ bakımından farklı derişimlere sahiptir.

Yalıncak Köyü eski içme suyu kaynağı, Bozbel Formasyonu içerisindeki tüfit seviyesinden boşalmaktadır ve bu seviye arsenikli suyun akiferini oluşturmaktadır. Formasyon volkanik kökenli kırıntılardan oluşan iki tüfit seviyesi içermektedir. Birinci tüfit seviyesi, formasyonunun taban seviyelerinde bulunmakta ve kalınlığ 500 m'dir [22]. Formasyon tabanında yer alan bu tüfit seviyesi, bu çalışmadaki birinci istif örneklemesine karşılık gelmektedir. İkinci tüfit seviyesi ise, formasyonunun orta düzeylerindeki Karababa tüfitleri olarak adlandirılan [22] tüfitler olup bu çalışmadaki ikinci istif örneklemesindeki tüfitlere karşılık gelmektedir. $\mathrm{Bu}$ tüfitlerin, özellikle Lütesiyen (Eosen) döneminde bölgenin yoğun volkanik faaliyetler sonucu ortaya çıkan malzemenin (volkanik kül, breş ve kayaç parçaları) derin deniz ortamında çökelmesiyle oluştuğu belirtilmektedir [22].

Sivas Havzası'nda yapılan diğer çalışmalar da Eosen döneminde havzanın farklı bölümlerinde bölgede yoğun bir volkanik aktivitenin olduğunu göstermektedir. Akçay ve Beyazpirinç [25], Sorgun ile Yıldızeli dolaylarında yitim veya çarpışmayla ilişkili volkanizmayla birlikte oluşan kırıntılı bir istifin olduğunu belirtmektedir. Bu kırıntılı istif, bu çalışmadaki Bozbel formasyonu ile benzerlik sunmaktadır. Almus, Yıldızeli ve Yıldızdağ bölgesinde 
yapılan çalışmada da özellikle Orta Eosen döneminde volkanik aktivitenin yaygınlaştığı ve bölgede dönemin volkano-sedimanter birimlerle temsil edildiği belirtilmektedirler [26]. Göçmengil vd. [26], Yıldızeli Havzası'ndaki Orta Eosen (Lütesiyen) volkanizmasının iki aşamada gerçekleştiği ve bunların yaklaşık 44 milyon yıl önce (birinci aşama) ve yaklaşık 40-41 milyon yıl öncesi (ikinci aşama) olduğunu belirtmektedir. $\mathrm{Bu}$ volkanizma yaşları, Bozbel formasyonu (Orta Eosen-Lütesiyen) içerisindeki tüfitlerin yaşları ile benzerlik göstermekte olup Yıldızeli Havzası'ndaki ilk aşama volkanizması, Hafik Havzası'ndaki Bozbel formasyonu'nun alt seviyesindeki tüfitlerle, ikinci aşama volkanizması ise Bozbel formasyonu'nun üst seviyesindeki tüfitlerle deneştirilebilir. Sivas Havzası'ında yapılan önceki çalışmalar, Eosen volkanizmasından kaynaklanan volkanik ürünlerin bölgede geniş yayılıma sahip olduğunu göstermektedir ve bu birimlerle ilişkili su kaynaklarının arsenik bakımından kirletilmiş olabileceğini düşündürmektedir.

Arseniğin doğal kaynaklarının, sülfit mineralleri, volkanik kayaçlar, hidrotermal kaynaklar ve fosil yakıtlar olabileceği belirtilmektedir ([27-29]). Bu çalışmada bölgedeki yeraltı sularındaki arseniğe volkanik kökenli arsenopirit ve borarsenat minerallerinin kaynaklık ettiği belirlenmiştir. Kurt [19] tarafından yapılan çalışmada, bölgedeki sularda arsenik ve bor element derişimlerinin benzer davranış sergilediği belirtilmiștir. Bu çalışmada da As ve $\mathrm{B}$ element derişimlerinin yüksek olduğu gözlenmiştir. Bu durum, bölge sularındaki arsenik kirliğinin Orta Eosen (Lütesiyen) yaşlı tüfitlerin içerisindeki arsenopirit ve borarsenat minerallerinin yeraltı suları tarafindan çözünmesinden kaynaklandığını göstermektedir. Türkiye'de özellikle Batı Anadolu'da yapılan bazı çalışmalarda ([12], [13], [30]) yeraltı sularında, bor cevherleşmesi ve volkanizma ürünleri ile ilişkili olduğu belirtilen arsenik kirliliğinden bahsedilmektedir. $\mathrm{Bu}$ çalışmalardan birinde [12], Balıkesir'in Bigadiç ilesi sınırları içerisinde yer alan bor yatağı civarındaki yeraltı sularında $900 \mu \mathrm{g} / \mathrm{L}$ 'yi aşan As derişiminin olduğu vurgulanmaktadır. Kütahya'nın Emet ilçesi sınırları içerisinde bulunan bor yatağı ve civarında yapılan bir çalışmada [30] da, cevherin ara katmanlarındaki tüfit ve killerde $20000 \mathrm{mg} / \mathrm{kg}$ 'lara kadar çıkabilen As derişimi olduğu ve bunun kökeninin volkanik küller, volkanik kayaçların ayrışma ürünleri ve sıcak su kaynaklarının olduğu belirtilmiştir. Bu çalışmada elde edilen sonuçlarla, Batı Anadolu'da yapılan çalışmaların sonuçları tüfit gibi bazı volkanik ürünlerle, bu ürünlere bağlı gelişen cevherleşmelerin ara katmanlarında yüksek miktarlarda As elementinin varlığını göstermektedir.

\section{Sonuçlar}

Sivas ilinin, Hafik ilçesine bağlı Yalıncak köyüne ait eski içme suyu kaynağındaki yüksek As derişiminin kökeninin aydınlatılmasına yönelik yapılan bu çalışmada elde edilen sonuçlar aşağıda verilmiştir.

Çalışma kapsamında arsenikli su kaynağının beslenim alanındaki Eosen dönemine ait volkanik ürünlerin (tüfit) $\% 0.14$ 'e varan miktarlarda $\mathrm{As}_{2} \mathrm{O}_{3}$ içerdiği belirlenmiştir. Mineralojik analizlerden elde edilen sonuçlara göre; tüfitler plajiyoklaz, klorit, klinopiroksen, ortopiroksen, arsenopirit ve borarsenat gibi mineraller içermekte ve tüfitlerde kloritleşme, serizitleşme ve karbonatlaşma türü alterasyonlar oldukça yaygın olarak görülmektedir. SEM-EDX analizlerine göre; bazı tüfit örneklerin noktasal olarak \%14'e varan miktarlarda elementel arsenik (As) mevcut olduğu ve bu arseniğin arsenopirit $(\mathrm{FeAsS})$ ve borarsenat $\left(\mathrm{BAsO}_{4}\right)$ mineral fazlarında bulunduğu belirlenmiştir. Sonuç olarak, Yalıncak köyü eski içme suyu kaynağındaki arsenik kirliliğinin, Eosen yaşlı Bozbel Formasyonu'nun alt seviyelerinde bulunan tüfitlerdeki arsenopirit ve borarsenat minerallerinin akifer ortamında meydana gelen su-kayaç tekpimeleriyle çözünerek yeraltı sularına geçtiği düşünülmektedir. Bölgede görülen arsenik kirliliğinin Eosen volkanizması ürünlerinden (tüfit) kaynaklanan doğal (jeojenik) bir kirlenme olduğu belirlenmiştir. Ayrıca, Sivas Havzası'ında Eosen volkanizmasının oldukça yaygın olması sebebiyle, bölgede henüz bilinmeyen ve yöre halkı tarafından kullanılan çok sayıda arsenikli su kaynağının olabileceği düşünülmektedir.

\section{Teşekkür}

$\mathrm{Bu}$ makale, B. F. Biçgel'in 2018 yılında tamamladığ 1 "Yalıncak Köyü (Hafik-Sivas) Eski İçme Suyu Kaynağındaki Arseniğin Kökeni" başlık yüksek lisans tezinden elde edilen veriler kullanılarak hazırlanmıştır. Çalışma kapsamında yürütülen arazi çalışmaları sırasındaki yardım, destek ve misafirperverliklerinden dolayı başta Sn. Musa Aktaş olmak üzere, Pirhüseyin ve Yalıncak mahalleleri halkına çok teşekkür ederiz. Bu çalışma, Mersin Üniversitesi Bilimsel Araştırma Projeleri Koordinasyon Birimi (MEÜ BAP 2017-2-TP2-2631 nolu proje) tarafindan desteklenmiş olup yazarlar bu desteğinden dolayı teşekkürlerini sunar.

\section{Çıkar çatışması}

Yazarlar çıkar çatışması olmadığını beyan etmektedir.

\section{Benzerlik oranı (iThenticate): $\% 5$}

\section{Kaynaklar}

[1] F. Yağmur ve İ. H. Hancı, Arsenik. Sürekli Tıp Eğitimi Dergisi, 11 (7), 250-251, 2002.

[2] P. L. Smedley and D. G. Kinniburgh, A review of the source, behaviour and distribution of arsenic in natural waters. Applied Geochemistry, 17 (5), 517-568, 2002.https://doi.org/10.1016/S0883-2927(02)00018-5.

[3] J. C. Ng, J. Wang and A. Shraim, A global health problem caused by arsenic from natural sources. Chemosphere, $52 \quad$ (9), 1353-1359, 2003. https://doi.org/10.1016/S0045-6535(03)00470-3.

[4] P. Bhattacharya, G. Jacks, S. H. Frisbie, E. Smith, R. Naidu and B. Sarkar, Arsenic in the environment: a global perspective. in: B. Sarkar (Ed.), Heavy Metals in the Environment, Marcel Dekker, Inc., pp. 147-215, New York, 2002.

[5] WHO, 1993. Guidelines for drinking-water Quality. World Health Organization. Genova.

[6] M. V. Brömssen, M. Jakariya, P. Bhattacharya, K. M. Ahmed, M. A. Hasan, O. Sracek, L. Jonsson, L. Lundell 
and G. Jacks, Targeting low-arsenic aquifers in Matlab Upazila, Southeastern Bangladesh. Science of The Total Environment, 379 (2-3), 121-132, 2007. https://doi.org/10.1016/j.scitotenv.2006.06.028.

[7] M. M. Rahman, R. Naidu and P. Bhattacharya, Arsenic contamination in groundwater in the Southeast Asia region. Environmental Geochemistry and Health, 31, 9. 21, 2009. https://doi.org/10.1007/s10653-008-9233-2.

[8] D. P. Shukla, C. S. Dubey, N. P. Singh, M. Tajbakhsh and M. Chaudhry, Sources and controls of Arsenic contamination in groundwater of Rajnandgaon and Kanker District, Chattisgarh Central India. Journal of Hydrology, 395 (1-2), 49-66, 2010. https://doi.org/ 10.1016/j.jhydrol.2010.10.011.

[9] N. Oruç, Emet-Kütahya içme sularında arsenik düzeyi, önemi ve bor yatakları ile ilişkisi. II. Uluslararası Bor Sempozyumu, sayfa 469-476, Eskişehir, Türkiye, 2325 Eylül 2004.

[10] M. Çöl and C. Çöl, Arsenic concentrations in the surface, well, and drinking waters of the Hisarcik, Turkey, area. Human and Ecological Risk Assessment: An International Journal, 10 (2), 461-465, 2004. https://doi.org/10.1080/10807030490438535.

[11] M. Çolak, Ü. Gemici and G. Tarcan, The effects of colemanite deposits on the arsenic concentrations of soil and ground water in Igdeköy-Emet, Kütahya, Turkey. Water, Air, \& Soil Pollution, 149, 127-143, 2003. https://doi.org/10.1023/A:1025642331692.

[12] Ü. Gemici, G. Tarcan, C. Helvacı and A. M. Somay, High arsenic and boron concentrations in groundwaters related to mining activity in the Bigadiç borate deposits (Western Turkey). Applied Geochemistry, 23 (8), 2462-2476, 2008. https://doi.org/10.1016/ j.apgeochem.2008.02.013.

[13] C. Helvaci, Stratigraphic and structural evolution of the Emet borate deposits, Western Anatolia. Dokuz Eylül University, Faculty of Engineering and Architecture, Research Paper MM/JEO-86 AR 008, 1986.

[14] E. Atabey, Nevşehir İli Tıbbi Jeolojik Unsurları ve Halk Sağlığı. Nevşehir Belediyesi, Nevşehir, 2013.

[15] M. Çeliker, S. Türkmen, C. Güler and M. A. Kurt, Factors controlling arsenic and selected potentially toxic elements in stream sediment-soil and groundwater-surface water systems of a hydrologically modified semi-closed basin (Uluova) in Elazı $\breve{g}$ Province, Eastern Turkey. Journal of Hydrology, 569, 167-187, 2019. https://doi.org/10.1016/ j.jhydrol.2018.11.067.

[16] M. A. Kurt, Ü. Yıldırım, C. Güler and O. Güven, Antimony and arsenic contamination in water from antimonite mineralization: a case study from Turhal (Tokat, Northern Turkey). Environmental Forensics, 2021. $\quad$ https://doi.org/10.1080/15275922.2021 .1907816.

[17] C. Simsek, Assessment of naturally occurring arsenic contamination in the groundwater of Sarkisla Plain (Sivas/Turkey). Environmental Earth Sciences, 68,
691-702, 2013. https://doi.org/10.1007/s12665-0121771-3.

[18] M. A. Kurt, Ü. Yıldırım, C. Güler ve E. Aktaş, Pirhüseyin ve Yalıncak köyleri (Hafik-Sivas) civarındaki bölgede bulunan yüzey ve yeraltı sularında arsenik kirliliği. 68. Türkiye Jeoloji Kurultayı, sayfa 72-73, Ankara, Türkiye, 06-10 Nisan 2015.

[19] M.A. Kurt, Pirhüseyin ve Yalıncak köyleri (Hafik, Sivas) dolaylarındaki suların arsenik konsantrasyonlarının belirlenmesi. Ömer Halis Demir Üniversitesi Mühendislik Bilimleri Dergisi, 7 (2), 532 540, 2018. https://doi.org/10.28948/ngumuh.443184.

[20] B. F. Biçgel, Yalıncak köyü (Hafik-Sivas) eski içme suyu kaynağındaki arseniğin kökeni. Yüksek Lisans Tezi, Mersin Üniversitesi Fen Bilimleri Enstitüsü, Türkiye, 2018.

[21] S. Korkmaz, Sivas havzasında ana kaya fasiyesi ve petrol oluşumunun organik jeokimyasal yöntemlerle araştırılması. Jeoloji Mühendisliği Dergisi, 37, 61-88, 1990.

[22] F. Kurtman, Sivas-Hafik-Zara ve İmranlı bölgesinin jeolojik ve tektonik yapısı. MTA Dergisi, 80, 1-32, 1973.

[23] F. Ay ve N. Yalçın-Erik, Ulaş (Sivas) kuzeyindeki Tersiyer yaşlı birimlerin petrol kaynak kaya ve organik fasiyes özellikleri. Cumhuriyet Üniversitesi Mühendislik Fakültesi Dergisi, 20 (1), 38-51, 2003.

[24] K. M. Önal, Sivas havzası derin yapısının jeofizik yöntemlerle incelenmesi. Yüksek Lisans Tezi, Cumhuriyet Üniversitesi Fen Bilimleri Enstitüsü, Türkiye, 2007.

[25] A.E. Akçay, M. Beyazpirinç, Sorgun (Yozgat)Yıldızeli (Sivas) Önülke havzasının jeolojik evrimi, havzada etkin olan volkanizmanın petrografik, jeokimyasal özellikleri ve jeokronolojisi. MTA Dergisi, 155, 1-32, 2017.

[26] G. Göçmengil, Z., Karacık, Ş.C., Genç, Billor, M.Z., ${ }^{40} \mathrm{Ar}-{ }^{39} \mathrm{Ar}$ geochronology and petrogenesis of postcollisional trachytic volcanism along the İzmirAnkara-Erzincan suture zone (NE, Turkey). TÜBİTAK Journal of Earth Sciences, 27, 1-31, 2018. https:// doi:10.3906/yer-1708-4

[27] J. Matschullati, Arsenic in the geosphere-a review. Science of the Total Environment, 249, 297-312, 2000. https://doi.org/10.1016/S0048-9697(99)00524-0.

[28] M. Bissel, F.H., Frimmel, Arsenic-a review. Part I: occurrence, toxicity, speciation mobility. Acta Hydrochim Hydrobiol, 31-1, 9-18, 2003. https://doi.org/10.1002/aheh.200390025.

[29] S. Wang and C.N., Mulligan, Speciation and surface structure of inorganic arsenic in solid phases: a review. Environment International, 34, 867-879, 2008. https://doi.org/10.1016/j.envint.2007.11.005.

[30] C. Helvac1, Occurrence of rare borate minerals: Veatchite-A, tunellite, teruggite and cahnite in the Emet borate deposit, Turkey. Mineraleum Deposita, 19, 217-226, 1984. 